\title{
Supporting the process of personal change in diabetes self-management during group education: Lessons learned from audio recorded sessions
}

\author{
Hilde Bastiaens*1 ${ }^{* 1}$ Linda Symons ${ }^{1}$, Patricia Sunaert ${ }^{2}$, Bernard Sabbe ${ }^{3}$, Paul Van Royen ${ }^{1}$ \\ ${ }^{1}$ Department of Primary and Interdisciplinary Care, University of Antwerp, Antwerp, Belgium \\ ${ }^{2}$ Department of General practice and primary health care, University of Gent, Belgium \\ ${ }^{3}$ Department of Adult psychiatry, University of Antwerp, Antwerp, Belgium
}

Received: January 3, 2016

DOI: $10.5430 / \mathrm{ijh} . v 2 \mathrm{n} 2 \mathrm{p} 1$
Accepted: February 29, 2016 Online Published: March 28, 2016

URL: http://dx.doi.org/10.5430/ijh.v2n2p1

\begin{abstract}
Objective: The objective of this paper is to describe the education process during a pilot group education program for people with type 2 diabetes in Belgium. The specific aims were to explore the personal change processes during the group sessions and to identify supporting and hindering elements in/for these processes.

Methods: We used a qualitative research approach from a constructivist perspective to study the education process during the group sessions. Two theoretical frames (trans-theoretical model and Strengths-Weaknesses-Opportunities-Threats (SWOT)matrix) were used to document changes in (motivation towards) self-management and to explore how the program influenced this change process.

Results: Supporting elements for personal change were identified and comprise: an empowerment attitude and tailored approach focusing on expectations and needs, the goal-setting process (mainly objectivizing current behaviour), peer support and using social support networks and community activities. Hindering elements include: providing extensive and detailed information not related to individual goals, the optional nature of the program in relation to active participation, too much focus on the expert role of the coaches and contextual barriers like an unsupportive environment/GP and co morbidity.

Conclusions: Based on the audio-recordings of the group sessions, we can conclude that many people did change their selfmanagement behaviour (or started reflecting on it) while following the program. We were able to document concrete changes people made but we could only identify a few links between specific program components and specific changes processes (e.g. pedometer, nutritional information). However, the SWOT analysis provided interesting knowledge that can inform future programs and support educators during group sessions. First, a flexible approach may be preferable to stage-specific approaches. In addition, the analysis drew attention to the fact that not everybody needs to change behaviour. What a program should aim for, is that everyone starts reflecting and subsequently takes an informed decision to change or not. Finally, diabetes educators should find a balance between their three different roles (expert, coach, and moderator) and should be provided with professional support.
\end{abstract}

Key Words: Type 2 Diabetes, Self-management education, Behavioural change, Qualitative research

\section{INTRODUCTION}

In chronic diseases like diabetes self-management is a fact. Patients manage their diabetes on a daily basis and the choices they make affect their health and wellbeing. ${ }^{[1-3]}$ The management of diabetes is complex comprising of medical treatment, behavioural issues like diet, physical activity, smoking cessation and dealing with psychosocial and emotional aspects of living with a chronic disease. Most

*Correspondence: Hilde Bastiaens; Email: hilde.bastiaens@uantwerpen.be; Address: Universiteitsplein 1, 2610 Wilrijk, Belgium. 
of the management relies on the patients themselves and involve changes in daily routines. For many patients selfmanagement is a difficult task.

Supporting people in becoming good self-managers is seen as a fundamental pillar of good diabetes management. ${ }^{[4-6]}$ Self-management education programs have shown to be able to support self-care. Both individual and group programs can be effective. ${ }^{[7,8]}$ Since the group of patients with diabetes type 2 continues to grow, group education seems a good option from an organizational and economic perspective. ${ }^{[4]}$ Evidence on the positive effects of group education on self-care activities, diabetes outcomes and quality of life is building up. ${ }^{[8-12]}$ While knowledge on diabetes is addressed in those programs, the emphasis is on supporting people in taking up self-management, so focusing on patients' behaviour. Although the potential benefits of group education are becoming clear, less is understood about which parts of these programs truly support people in thinking about and realizing changes in self-management, in living and dealing with diabetes. ${ }^{[7,8,13]}$ In order to maximize the impact and efficiency of group programs, a useful addendum to trial outcomes is to explore in greater depth the education process itself.

Therefore the objective of this paper is to describe the education process in a pilot group education program in a well determined Belgian region (Aalst). ${ }^{[14]}$ The program was set up in primary care as part of a complex regional intervention guided by the Chronic Care Model. ${ }^{[15]}$ The aim of the group offer was to support people with type 2 diabetes (T2D) in becoming/staying motivated to self-manage their illness (focus on dietary habits and physical activity) and in defining and implementing their own behavioural goals. We wanted to help people reflect upon their own role in diabetes management and make self-defined changes within the context of their own lives. The program was build up and carried out from an empowerment point of view and used existing evidence on self-efficacy and behaviour change. The trans-theoretical model (TTM) and the social cognitive theory (SCT), both explanatory models for behaviour change, were used as theoretical guiding principles to work out the group program. ${ }^{[16-18]}$ The TTM is a stage theory looking at behaviour change as a stepwise process and using different stages of readiness to change. Each stage requires different interventions to support change to a next stage. Using stage specific interventions, health care professionals can facilitate change. The SCT emphasizes the importance of enhancing a person's behavioural capability (knowledge and skills) and self-confidence (self-efficacy). The latter is a powerful predictor of health behaviour. ${ }^{[16,19]}$ Both models refer to individual goal setting as a way to support behaviour change.
The target population of the group program were people with T2D living in the study area and receiving less than 2 insulin injections a day. Patients could be referred by their general practitioner (GP) or came on their own initiative (following a community information campaign or after following one to one education offered in the region). Within the pilot setting, the program was offered five times. The full program comprised five basic 2-hour sessions every two weeks and one follow up session 3 months later. The coach was a diabetes trained nurse who was variably supported by a dietician or psychologist. In brief, the key points of the program were: support people in reflecting on their self-management and their own role in self-management, stimulate reviewing their own self-care behaviour (within the context of their everyday lives) and offering tools for assessing actual behaviour (for example a pedometer), help people in defining their own goals (physical activity, diet) and making a detailed action plan, addressing barriers and solutions and give information on demand. The program was built up in a way that people in different stages of readiness to change could be supported. A detailed description of the program content and evaluation of the effectiveness was reported elsewhere. ${ }^{[14]} \mathrm{A}$ brief overview of the content of the sessions can be found in Table 1.

The pilot program was able to improve HbA1c, BMI and quality of life at 12-months follow-up. In a next step we wanted to explore which parts of the program triggered changes that might have led to these improvements. Consequently the specific aims of the present study are to explore the personal change processes during the group sessions and to identify supporting and hindering elements in/for these processes. The idea was that by identifying these hindering and supporting elements in the process of choosing and implementing goals, in changing self-management behaviour (and attitudes towards self-management and diabetes) we would find cues which could improve our program, inform future programs and support educators by providing practical tools and attention points.

\section{Methods}

\subsection{Design and data-collection}

We used a qualitative research approach from a constructivist perspective to study the education process during the group sessions. We wanted to learn about personal change processes in diabetes self-management and about supporting and hindering elements for change by listening to/reading real life group education sessions, analysing and interpreting this material on the different experiences and processes of individual participants. 
Table 1. Overview of the content of the group program per session ${ }^{\S}$

\begin{tabular}{|c|c|c|c|}
\hline Session & Providers & Key points & Home work \\
\hline Session 1 & $\begin{array}{l}\text { Educator } \\
\text { Psychologist }\end{array}$ & $\begin{array}{l}\text { Introduction - aims of the program } \\
\text { Explore motivation to participate } \\
\text { Explore own expectations } \\
\text { Basic information on diabetes and lifestyle }\end{array}$ & $\begin{array}{l}\text { Think about taking up } \\
\text { self-management of diet } \\
\text { and exercise }\end{array}$ \\
\hline Session 2 & $\begin{array}{l}\text { Educator } \\
\text { Dietician } \\
\text { (Phys. Activ. counsellor) }\end{array}$ & $\begin{array}{l}\text { Introduction of goal setting (with Examples/ experiences of } \\
\text { the group) } \\
\text { Basic information on healthy food and exercise } \\
\text { How to assess actual behaviour }\end{array}$ & $\begin{array}{l}\text { Assessment (Food } \\
\text { diary)/(Pedometer) } \\
\text { Think about an individual } \\
\text { goal }\end{array}$ \\
\hline Session 3 & $\begin{array}{l}\text { Educator } \\
\text { (Phys. Activ. counsellor) }\end{array}$ & $\begin{array}{l}\text { Feedback on behaviour (assessment) } \\
\text { Setting concrete goals } \\
\text { Making an action plan }\end{array}$ & $\begin{array}{l}\text { Make an action plan } \\
\text { Think about } \\
\text { barriers/solutions } \\
\text { Start change }\end{array}$ \\
\hline Session 4 & $\begin{array}{l}\text { Educator } \\
\text { Dietician }\end{array}$ & $\begin{array}{l}\text { Discussing concrete goals and action plans } \\
\text { Discussing barriers/solutions } \\
\text { Feedback on food diary }\end{array}$ & $\begin{array}{l}\text { Adjusting goals or plans } \\
\text { Implement actual change } \\
\text { Problem solving }\end{array}$ \\
\hline Session 5 & $\begin{array}{l}\text { Educator } \\
\text { Psychologists }\end{array}$ & $\begin{array}{l}\text { Discussing experiences } \\
\text { Discussing barriers and solutions } \\
\text { Problem solving } \\
\text { Discussing concrete goals and action plan for the following } \\
3 \text { months + confidence }\end{array}$ & Idem session 4 \\
\hline $\begin{array}{l}\text { Follow up } \\
\text { session }\end{array}$ & $\begin{array}{l}\text { Educator } \\
\text { Dietician }\end{array}$ & $\begin{array}{l}\text { Discussing experiences } \\
\text { Adjusting goals/action plans } \\
\text { Problem solving }\end{array}$ & Idem session 4 \\
\hline
\end{tabular}

Note. ${ }^{\S}$ Published in Primary Care Diabetes, 2009; 3: 103-109.

Data used for this study consisted out of the audio-recordings of the actual group sessions (five groups, 6 sessions per group). In addition, a group interview was organized after the fifth session of each group. The aim was to explore people's experiences with the program using a short script focusing on working with individual goals, working in a group of peers and getting support from trained coaches. This group interview was led by a member of the overall project, who was not involved in the group sessions, and was audio-recorded.

Ethical approval was requested and obtained from the Ethical Committee of the University of Antwerp and the University of Ghent (2004/253).

\subsection{Participants}

Forty-four patients followed group education (see Table 2). Each group comprised of 8 to 10 patients. We did not steer the composition of the groups based on certain characteristics. Patients participated in the group of their choosing based on their availability on the dates of a series of 6 sessions. The mean age of the participating patients was 66 years and fiftythree percent were men. Education levels ranged from only attending primary school (followed education till 14 years of age) till having a university degree. All groups had mixed education levels. All but two patients were retired. On average patients were diagnosed with diabetes for 5 years and their mean baseline $\mathrm{HbA1c}$ and BMI respectively were 7.4\% and $28.6 \mathrm{~kg} / \mathrm{m}^{2}$. The mean attendance rate for the first five sessions was 4.1. The session attendance rate varied from 63 to $100 \%$. Forty-eight percent of the participants attended all basic sessions. Half of the non-attended sessions were cancelled in advance mainly because of sickness or holidays. All patients gave a written consent for participating in the program and in the subsequent evaluation process.

Table 2. Baseline characteristics of the participants

\begin{tabular}{|ll|}
\hline Male gender (\%) & $53 \%$ \\
$\begin{array}{l}\text { Mean age }( \pm \text { SD) } \\
( \pm \text { SD) }\end{array}$ & $66( \pm 6)$ \\
$\begin{array}{l}\text { Number of people diagnosed with T2D for over } \\
10 \text { years }(\%)\end{array}$ & $5( \pm 5)$ \\
Mean HbA1c at baseline $( \pm$ SD) & $9(20 \%)$ \\
Mean BMI at baseline $( \pm$ SD) & $7.4 \%( \pm 1.3)$ \\
Mean number of basic sessions attended & $28.6 \mathrm{~kg} / \mathrm{m}^{2}( \pm 18)$ \\
\hline
\end{tabular}

\subsection{Data-analysis process}

Data-analysis was based on transcriptions and audio recordings and was undertaken by two researchers (HB and LS). $\mathrm{HB}$, the principal investigator, was involved in the program 
development and was present at one session of each group as an observer. The second researcher (LS) is a psychologist who was familiar with the program aims but was not involved in its development or implementation. The study supervisor (PVR) and two additional researchers (BS who is a psychiatrist and PS who is a GP and is familiar with the research project) were involved in the reflective processes during the analysis process.

The analysis was performed in three steps: 1) familiarization with the material, 2) identifying changes in self-management motivation or behaviour, 3) identifying supportive and hindering elements for these changes.

\subsubsection{Familiarization with the material}

First the principal investigator (HB) listened to all the material in order to identify the group with the clearest and richest discourses to start the analysis on. Next, two researchers (HB and LS) listened to the recordings and read the transcripts of this group (group 4). In addition, the first 2 sessions of groups 2 and 3 were explored. The main purpose of this first step was to get familiar with the material. We paid attention to the participants' narratives, the coaches' contributions, and to the mutual interactions between participants and between participants and the coaches.

\subsubsection{Identifying changes in self-management motivation or behaviour}

In a second step, we set out to use the trans-theoretical model of change to explore the personal change processes in diabetes self-management (dietary habits and physical activity). This model describes 6 stages of readiness to change (see Figure 1). ${ }^{[16]}$ We set out to assign quotes to specific stages based on the specificities of each stage as described in Figure 1 (e.g. 'I drink three beers every evening and I feel good doing that'). We specifically looked for quotes documenting changes between stages (e.g. between pre-contemplation and contemplation: "I thought I was quite active but after using the pedometer I realized I probably am not active enough and I should think about doing more physical activity"). Since the total group program only ranged over 5 months, maintenance and relapse were not used in the analysis.

\subsubsection{Identifying supportive and hindering elements for change}

In this step we used the Strengths-Weaknesses-OpportunitiesThreats (SWOT) matrix. This is a frame that can be used to describe strengths and weaknesses of a program in relation to reaching a specific goal and to make an overview of external conditions that can be an opportunity or a threat for reaching that goal. Subsequently, a SWOT analysis is performed putting the program's strengths and weaknesses in relation to the context of external opportunities and threats.
For our study, the different elements of the SWOT-matrix were operationalised as follows (see Table 3 ). The desired goal/objective of the program was "personal change in (thinking about) self-management". The group-program was defined as the "internal system". So we looked for the strengths and weaknesses of the program in relation to supporting patients (in becoming motivated) to self-manage their illness (dietary habits and physical exercise). In addition we focused on the opportunities and threats to the change process from outside e.g. the patient and his/her environment (including health care providers). The SWOT analysis for our study is described in Table 4: How did/can we use the strengths of the program to take advantage of opportunities within the patients and their environment and avert its' threats? In what way $\mathrm{did} / \mathrm{can}$ weaknesses of the program prevent using opportunities or ward off threats?

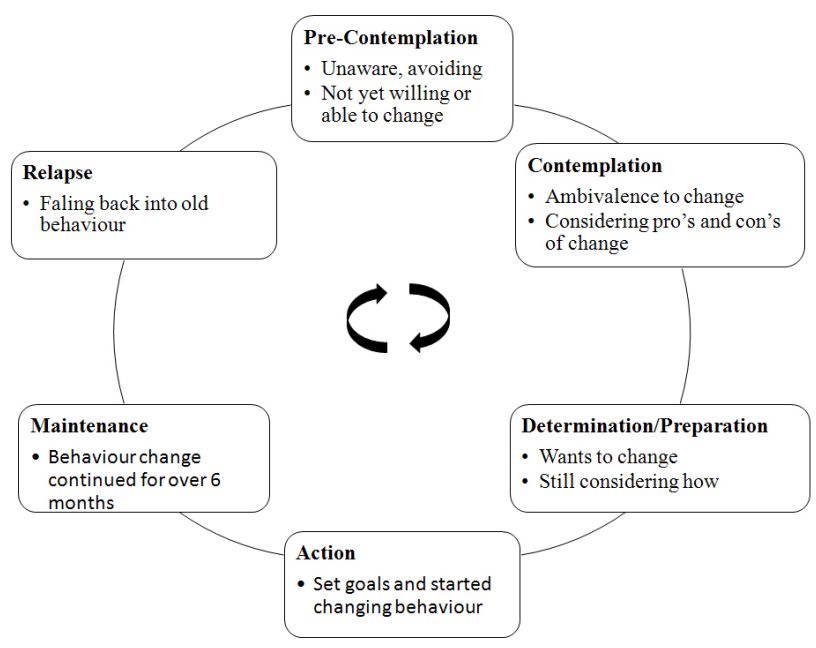

Figure 1. Trans-theoretical model of change

Table 3. SWOT matrix for supporting or hindering elements for personal change

\begin{tabular}{|c|c|c|}
\hline Internal system: & Strengths: & Weaknesses: \\
\hline Group program & $\begin{array}{l}\text { Elements of the } \\
\text { course that are } \\
\text { supportive for the } \\
\text { change process of } \\
\text { patients }\end{array}$ & $\begin{array}{l}\text { Elements of the } \\
\text { course that are } \\
\text { hindering for the } \\
\text { change process of } \\
\text { patients }\end{array}$ \\
\hline External system: & Opportunities: & Threats: \\
\hline $\begin{array}{l}\text { Patients and their } \\
\text { environment }\end{array}$ & $\begin{array}{l}\text { Elements outside } \\
\text { the course that are } \\
\text { supportive for the } \\
\text { change process of } \\
\text { patients }\end{array}$ & $\begin{array}{l}\text { Elements outside the } \\
\text { course that are } \\
\text { hindering for the } \\
\text { change process of } \\
\text { patients }\end{array}$ \\
\hline
\end{tabular}

To identify the supporting and hindering elements for change, qualitative content analysis using the SWOT-matrix was employed. ${ }^{[20-22]}$ Content analysis is a context-sensitive and 
flexible method to analyse qualitative data. In a first step, two researchers (HB and LS) re-read and coded all the transcripts of group 4. Open codes were used to label material related to supporting or hindering elements to personal change as interpreted by the researchers (e.g. "I do not have any symptoms, that is the problem" - this was interpreted as a threat; "I want to learn from others, that is why I am here in the program"- this was interpreted as an opportunity).
Subsequently, open codes were grouped within the different elements of the SWOT-frame as defined above. Quotes related to the program (the actual discussions, interactions in the group, the tools used and, the interventions and attitudes of the educators) were coded into strengths and weaknesses. Quotes related to the participants or their context which could potentially influence the personal change processes were categorized as opportunities or threats.

Table 4. SWOT analysis

\begin{tabular}{lll}
\hline & Strengths & Weaknesses \\
\hline \multirow{2}{*}{ Opportunities } & $\begin{array}{l}\text { How can we use the strengths of the program to take } \\
\text { advantage of opportunities within patients and their } \\
\text { environment? }\end{array}$ & $\begin{array}{l}\text { How can weaknesses of the program prevent taking } \\
\text { advantage of opportunities within patients and their } \\
\text { environment? }\end{array}$ \\
\hline \multirow{2}{*}{ Threats } & $\begin{array}{l}\text { How can we use the strengths of the program to counter } \\
\text { threats from within patients and their environment? }\end{array}$ & $\begin{array}{l}\text { How can weaknesses of the program inhibit tackling } \\
\text { threats from within patients and their environment? }\end{array}$ \\
\hline
\end{tabular}

After the coding of each session of group 4, researchers discussed and reflected on this coding process. A third researcher (PVR, study supervisor) participated in these discussions. Next, transcripts and audio material from the other groups were analysed and the developing SWOT-matrix was adapted using a constant comparison process between the analysis results and the material. Finally, the results were discussed and reflected on with additional researchers (BS and PS).

\section{Results}

An overview of the results from the two analysis steps is provided below. First we address the results of the analysis using the TTM. Next the group program's strengths and weaknesses are described in relation to contextual opportunities and threats.

\subsection{Results of the analysis of personal change processes during group sessions using the trans-theoretical model (TTM)}

In the analysis using the TTM, we wanted to depict the personal change processes based on the conversations during the sessions. Since the program used goal-setting as a way to support patients in self-managing their illness, we assumed to find quotes in which people describe their changes including "how" and "why". However, we experienced that, based on the material we had to our disposal (recordings and transcripts of the sessions), this was not possible. We observed that what people said during the sessions, their spontaneous conversations were not that straightforward. Quotes were seldom structured and detailed in a way that people linked what they did change (attitudes or behaviour) with "why", "how" and "what helped". Only a few times discourses were

Published by Sciedu Press found where people described a process as in quotes (1), (2) and (3). The patient from the first quote did change her behaviour: she walks more. She talks about her attitude: "you need a strong character" and we come to know what helps her to change (pedometer - "counting steps"). She encountered obstacles and learned that sitting down first was not a good idea. She continues, maintains her new behaviour, maybe because her sugar is better and probably because she experienced that walking gives her some peace.

(Quote 1) PARTICIPANT (PART): "Using a pedometer really helps. My sugar is now much better. But you need a strong character. Before, I sat down in my chair after doing the dishes. And now, I put on my coat and I go walking. But I have to do it immediately after finishing the dishes because when I first sit down, then...

I find walking positive in two ways. You've got your exercises (steps) and you've got inner peace. Because when you walk, you meet people, like a mother teaching her child to ride a bicycle. That really gives me inner peace." (group 4)

(Quote 2) PART: "When you measure you know something but first you already need to know what to measure: weight, number of steps, read the food labels. I didn't used to do that but now I look at the amount of carbohydrates in food because we learned to do that. If you know that kind of things, you can manage your diabetes." (group 1)

(Quote 3) PART: “When you measure you know something but first you already need to know what to measure: weight, number of steps, read the food labels. I didn't used to do that but now I look at the amount of carbohydrates in food because we learned to do that. If you know that kind of things, you can manage your diabetes." (group 1) 
So we did observe that many people actually changed their self-management behaviour and attitudes during the period they attended the group sessions. Yet, most people mainly talked about the actions they took as is illustrated in quotes (4) and (5). So we did not encounter a lot of clear, spelled out transitions between stages.

(Quote 4) PART: "I lost $8 \mathrm{~kg}$. Now we use olive oil to cook and pay attention to what we eat. We used to eat a lot of meat which we don't do anymore." (group 4)

(Quote 5) PART: “I don't put anything on the stairs anymore. I bring it upstairs immediately, even if this means doing that 20 times in one day." (group 4)

During the analysis process we also noticed that people could be in different stages for different self-management behaviours, e.g. being ready to increase physical activity but not being prepared to change dietary habits (6). We also noticed that some people did not change their behaviour but did start to reflect on their current self-management behaviour, so moving from pre-contemplation into contemplation (7).

(Quote 6) PART: “...exercising, yes I regularly leave the car aside - because of two reasons: exercising and the price of the gas -...But I still have the problem of having to lose weight. And I am reluctant to do that."(group 1)

(Quote 7) PART: "For me it is important to keep being aware that I have a problem. Because I don't feel it in my daily life. I need to be aware that I should take up healthy eating and exercising. But at this moment I did not make any concrete changes yet...." (group 1)

\subsection{The programs' strengths and weaknesses in relation to contextual threats and opportunities}

We recognized a number of strengths of the program in relation to helping people change their self-management behaviour (or intention to change). Educators definitely had an empowering attitude: e.g. no blaming, confirming what people did well, not handing solutions. An individual-centred approach was realized for a considerable part of the sessions. Patients' questions lead to tailored and individualized information provision, and patients' own experiences were taken into account. (8)(9) The general information on diabetes that was provided increased the patients' knowledge. (10) The processes of goal setting and goal striving was supported by objectivizing current behaviour (pedometer), triggering reflection on prior experiences, possible barriers and solutions, and possible support from the environment. (11) We observed that the group sessions were able to provide peer support and that they had an implicit effect on GP behaviour. Patients reported that because they felt more able to ask questions, and because GPs knew they were attending an education program, GPs gave more attention to diabetes care. (12) (13)

(Quote 8) EDUCATOR (ED): "So we are here to help you discover what is important to you, what you would like to change and support you in doing so."(group 3)

(Quote 9) ED: “If you like to work on something in particular, if you want certain topics to be covered, just ask." (group 2)

(Quote 10) PART: "And now I know that diabetes is about more than sugar in your coffee. So, now I try to adapt to it (the advises on diet). I already lost 8 kilograms." (group 4)

(Quote 11) PART: “Using the pedometer really motivated me to exercise more. When I didn't have enough steps yet, I went out and walked another round." (group 4)

(Quote 12) PART: "You realize you are not the only one with the problem and that gives you courage. (group3)

(Quote 13) PART: “...since he (GP) knows I come here to the program, he started talking about diabetes....” (group 4)

We also identified a number of important weaknesses of the program. First, a lot of time was spend on giving very detailed information, both during the pre-planned information parts and while answering participants' questions. An illustrative quote is given below (14). This conversation took about 30 minutes, most of it by the dietician. And there were several of these discourses per session often evoked by patients who kept asking more details. These program parts took up a lot of time but were not goal-focused and triggered new questions. A second weakness, related to the first was the "optional" nature of the program e.g. patients were free to use tools offered, to decide whether they wanted to set goals, etc. Together with the focus on detailed information this sometimes led to participants "running" the sessions and getting into details, no longer related to the goals people were working to. Another weaknesses identified was the use of "we" in a way that it seemed to mean "we" the health care providers who are in charge and know best ("the diabetes police”) as shown in quotes (15) and (16).

(Quote 14) PART: “I eat a lot of fibres... don't take white biscuits, eat a lot of fruits... I eat half a banana... Grapes?... Apples: sugar?... Watermelon... milk... Soymilk... calcium... destroy fats... no meats but cheese... beer... Porto... prunes... raisins...” (group 3)

(Quote 15) PART: “We allow potatoes, they are healthy...but for a patient with diabetes we still have to be careful that we don't eat too much potatoes...” (group 1)

(Quote 16) PART: “We allow that sometimes now, previously we were a lot stricter in that...” (group 4) 
Opportunities are important elements associated with the patients or their environment which the program did/could use to support people in thinking about and improving their self-management. Expectations, motivations and personal needs participants raise during the introduction, are important opportunities for the program to use to support personal change. A lot of people mentioned they attended the sessions because they liked to know if they were "doing ok".(17)(18) Furthermore, many people "wanted to learn from others" and "share experiences".(19) Also (previous) successes could be drawn upon to help people change their health care behaviour. Some people talked about social support networks as possible facilitators for increasing (e.g. physical activity programs in the community, friends and spouses).(20)(21)(22) It should be an attention point for educators to take advantage of this information patients provide during the sessions. Since the program was organized at the community level, existing activities in a trusted environment were available and should be/were used.(23) In general we noticed that making use of these opportunities during the sessions is not always easy, especially when they concern psychosocial or emotional needs of the participants.

(Quote 17) PART: "For me, the most important thing is to know if I'm on the right track concerning my diet. With the snacks I take, the fruit I eat." (group 4)

(Quote 18) PART: "I come here to get support because I lack motivation to do what I have to do." (group 2)

(Quote 19) PART: "That is my biggest problem, when I think about diabetes too much, I get depressed. And that is the reason I came here, to see how other people are coping with this." (group 4)

(Quote 20) PART: "Riding a bicycle on your own is not motivating and therefore I think I should join a cycling group again." (group 4)

(Quote 21) PART: "In relation to my nutritional habits, I started, thanks to my lady friend, to eat less and eat differently." (group 1)

(Quote 22) PART: "For me, if I could make an appointment with someone to exercise together, then you have a kind of responsibility towards that person and that would motivate me because you can't let that person dawn." (group 5)

(Quote 23) PART: "Today I will start with "run yourself fit". ED "Did you list with the program?" PART "Yes, I did. I think it is important to exercise." (group 4)

Finally some threats were acknowledged. These are elements related to the participants or their context which we identified as potentially hindering to the process of change and were/should be taken up by the coaches during the sessions. Very striking was the lack of support a number of people got from their GP. A lot of people got very little information, felt their GP thought of their diabetes as "a minor problem" and was not clear about the diagnosis. This kind of attitude can obviously threaten good diabetes self-care. A group of people did get information but often in a very general form, not tailored to their needs. (24)(25) Another major treat identified were negative emotions like difficulties in accepting diabetes and the very prominent feeling of "loss" (you can't do anything anymore, are not allowed anything). The latter was related to a feeling of guilt (when not managing diabetes as you are supposed to). (26)(27) Furthermore a lot of people were anxious about getting complications. A treat which intertwines with the previous ones, was getting judged (or pressured) by and being confronted with negative comments from others on self-management behaviour. In general a non-supportive environment was identified as an important treat. (28)(29) The fact that diabetes is often asymptomatic can threaten (active) self-management. For other participants co morbidity, physical limitations and complications (hypoglycaemia included) formed a treat to (taking up) self-management. (30)(31) A number of participants also mentioned other contextual barriers (time, season) for changing self-management behaviour. (32)

(Quote 24) PART: “Doctors don't tell you much. Maybe because they are too busy? They seem to go over it lightly, ignore it." (group 4)

(Quote 25) PART: "It (blood glucose) is borderline he tells me. You don't have diabetes yet. But he did write me a prescription for diabetes medication. So I don't know." (group 4)

(Quote 26) PART: "My biggest problem is accepting my diabetes. ED "What is the most difficult?" PART "The restraints, the risks, having to deal with lots of different things. I struggle with that and then I get angry and that in turn leads to being indolent. And when you are a little depressed then you fail to do anything." (group 4)

(Quote 27) PART: "When I eat something, I immediately feel guilty because I feel I am shortening my life." (group 4)

(Quote 28) PART: “...I am anxious of going blind because then you become dependent on other people. I am really frightened that should happen. It really occupies me." (group 4)

(Quote 29) PART: “When you are at someone else's, you cannot say no (when they offer something to eat)." (group 3)

(Quote 30) PART: "I neglected my diabetes because I feel 
fine. I don't have any pain.” (group 2)

(Quote 31) PART: “I have a bad back so I don't exercise a lot." (group 4)

(Quote 32) PART: "During the winter you actually do fewer sports because it is dark soon. And I cannot exercise during the day because I have to work "(group 3)

Table 5 summarizes the SWOT-analysis performed on the strengths, weaknesses, opportunities and threats of/to the program to support the patients' change processes. The meaning of these results, is elaborated on in the discussion.

\section{Discussion}

We evaluated a group program that intended to support people with diabetes type 2 in becoming/staying motivated to self-manage their illness (dietary habits and physical activity) and in defining and implementing their own behavioural goals. The objective of the evaluation was to explore the personal change processes during the group sessions and to look into what (within and outside the program) really supported or hindered patients in this process. We based the analyses of the audio-recorded sessions on two theoretical frameworks.

\subsection{Discussion of the findings}

The SWOT matrix turned out to be the most useful model in the analysis process. Once the different components were defined, the SWOT-analysis supplied interesting material and we did gain interesting knowledge to amend the content and processes of the program. Analysing this material triggered reflection on and partially provided answers to the following kinds of questions: "How much of the program content do you determine upfront?", "To what extend should patients be able to control, determine the session content and process?", ...The fact that we mainly learned something on the program processes is not surprising since the material we used were the recordings of the actual education sessions. We learned something about the processes interactions in relation to the intentions of the program. The stages of change framework was found to be a less suitable model for ordering the study material since few clear transitions and individual change processes could be identified. Nevertheless, a number of useful lessons can be learned about how to support patients during group sessions to change (think about changing) their self-management behaviour. Details and discussion on the findings are provided in the next paragraphs.

\subsubsection{Trans-theoretical model: lessons learned during the analysis process}

First, elements out of different stages are spoken about by different people and that could be regarded as a strong point of our program. It indicates that during the sessions the 8 group is willing and able to reflect on change. Second, we illustrated that participating patients were in different stages of readiness to change and that individual patients could be at different stages for different behaviours. This further underpins the idea that flexible approaches may be preferable to stage-specific approaches, especially in group education. Other researchers have equally wondered whether to customize treatment to a specific stage or to provide a more broad-spectrum intervention (what we did). ${ }^{[23-26]}$ Next, the analysis process in this study prompted that not everybody must necessarily change his/her behaviour. What a program should aim for is that everyone starts a reflection process and subsequently takes an informed decision to change or not to change (at that moment or in the future). That represents a true empowerment philosophy. ${ }^{[1,2]}$ So to be a real empowerment based program, it needs to focus on the reflection process of everyone and the behaviour change process for those who decide to take that step. A concrete behavioural change is not necessarily the only worthwhile goal of the program. Supporting people in thinking about change could lead to change later as other authors described equally. ${ }^{\text {[27] }}$ Finally, since verbalizing is difficult for people this could mean they do not see the connection between barriers and behaviour, between supportive elements and behaviour. This could be a focus for the coaches during the sessions.

\subsubsection{SWOT-analysis: lessons learned on program con- tent and processes}

Thanks to the programs' strengths, mainly the empowerment attitude and tailored approach, most of the threats we identified could be, and were averted to a large extent by the program and the coaches (see Table 5). In practice this comprised giving tailored and practical information (including on complications), going into psychosocial and emotional issues (fears, feelings), addressing how to deal with the environment and paying attention to what the participants were already doing well. Using a group approach (peer contact) contributed to countering some threats. Providing information and going into barriers and facilitators (during the goal setting process) helped to deal with threats like "not having any symptoms", co morbidity and contextual barriers. Similarly, a number of opportunities were seized by the coaches by going into personal experiences and concerns. Using tailored and concrete goal-setting as a strategy in the program, also contributed thereby. Finally the program used the community setting and made a list of local physical and social activity groups. Most of this is realized by the educators what points to the crucial role they play. The program had an indirect impact on GPs, stimulating them to pay more attention to diabetes. This is an important finding because it is positively related to continuity in self-management support which is regarded as important for sustained effects. ${ }^{[4-7]}$

ISSN 2377-7338 E-ISSN 2377-7346 
Table 5. Summary of the SWOT- analysis

\begin{tabular}{|c|c|c|c|}
\hline & & \multicolumn{2}{|l|}{ Program } \\
\hline & & Strengths & Weaknesses \\
\hline & & Using strengths to take advantage of opportunities & $\begin{array}{l}\text { How can weaknesses prevent taking advantage of } \\
\text { opportunities? }\end{array}$ \\
\hline & Opportunities & $\begin{array}{l}\text { - Personal expectations and needs were partly } \\
\text { taken into account by the patient-centred and } \\
\text { tailored approach and the empowering attitude } \\
\text { of the coach. } \\
\text { - Using community physical activity programs } \\
\text { can help in making a concrete action plan } \\
\text { - Since people want to learn from each other more } \\
\text { advantage can be taken of the group setting by } \\
\text { stimulating and supporting group interaction }\end{array}$ & $\begin{array}{l}\text { - Focusing too much on information and letting } \\
\text { participants run the sessions to a large extend } \\
\text { did/can cause leaving needs of participants } \\
\text { unaddressed (mostly psychosocial or emotional } \\
\text { needs). } \\
\text { - The limited amount of real interaction could } \\
\text { prevent the process of participants wanting to } \\
\text { learn from peers. }\end{array}$ \\
\hline \multirow{2}{*}{ Context } & & Using strengths to counter threats & How can weaknesses inhibit tackling threats? \\
\hline & Threats & $\begin{array}{l}\text { - The program had an indirect effect on the } \\
\text { relationship between some of the patients and } \\
\text { the GP (patients asks questions, GP is more } \\
\text { interested in diabetes) } \\
\text { - Using a tailored (person-centred) approach, } \\
\text { taking patients' needs into account and } \\
\text { employing an empowerment attitude did/can } \\
\text { partially alleviate negative emotions. } \\
\text { - Addressing patients own questions, experiences } \\
\text { and needs and using goal setting can help deal } \\
\text { with barriers as 'not having any symptoms', } \\
\text { tackling self-management when co morbidity is } \\
\text { present and can help learning to deal with an } \\
\text { unsupportive environment }\end{array}$ & $\begin{array}{l}\text { - Giving a lot of detailed information and } \\
\text { sometimes taking the 'we health care providers } \\
\text { know what is best' attitude could augment } \\
\text { negative feelings and accentuate the lack of } \\
\text { support received from GPs and a non-supportive } \\
\text { environment. } \\
\text { - The optional, free approach towards } \\
\text { participation in goal setting and change } \\
\text { processes could prevent participants from } \\
\text { actually dealing with treats as feeling no } \\
\text { symptoms or not trying to improve } \\
\text { self-management of diabetes because of the } \\
\text { presence of complications or other pathologies. }\end{array}$ \\
\hline
\end{tabular}

Overall our observations are that as a consequence of the weaknesses (still a large focus on information and the optional nature of active participation) a number of self- management needs which were raised (opportunities) were somewhat neglected. What's more, it triggered participants, and also the educators, to stay on the level of information gathering, providing information, hampering the reflection about and response to participants' own behaviour and perhaps limiting interaction in the group. It could also have prevented countering some threats to change like negative emotions and fear for complications. This is in line with other research indicating that less educator talk in a session will lead to greater change in participants' beliefs about their diabetes. ${ }^{[28]}$ We noticed that the program still focused too much on the expert-role of the educator, resulting in giving very detailed information and actually giving lectures. It could have set a "trend"/"standard" and created the expectation of looking to the expert for answers and not trying to find them as a group. Maybe it even implicitly gave patients the impres- sion that they should know everything, which could be a treat to their self-efficacy (since knowing all seems necessary and is impossible). There are many possible hypotheses for the fact that a lot of information was provided although that was not our intention. A first explanation could be that the expert role is what educators know best are most comfortable with. Next, focusing on only 2 specific topics might have triggered going into a lot of details. Finally, our findings also point to the possibility that educators were dragged into providing a lot of detailed information by serial questions of participants. In the current program we focused on diet and exercise and maybe that lead to leaving important needs unspoken. So in future programs maybe we should leave the choice of topics to the participants and if not spoken about, raise (add) crucial topics in the end. However, on the one hand a certain structure is needed to support participants' trough the goal setting process. On the other hand too much structure could hinder people's own journey of change. ${ }^{[1]}$ Reconciling "no obligation to change" and taking goals setting as a focus 
in the program seems sometimes contradictory. Based on the experiences in this study we believe a certain level of involvement is necessary. People are free to change or not change their behaviour but at the same time asking to engage in reflection about one's behaviour is what we can do (e.g. reflection on pros and cons of actual behaviour, think about what you find important, ...).

\subsection{Limitations and strengths}

The use of audio recordings of "real life" sessions imposed certain limitations. First, it was not possible to follow the trajectory of each individual separately. This restricted the possibility to describe personal change processes within individuals over the course of the sessions. Subsequently, we were not able to link many specific program elements to concrete changes in particular patients. In order to obtain that kind of information we need to be able to document individual trajectories in more detail. By using more focused approaches to data collection (e.g. individual serial interviews) specifically asking to describe the change process and elements which were supportive or hindering could provide more insight in transition between stages. ${ }^{[29]}$ If videorecording would be acceptable for participants, this could also provide more detailed information. Another objection could be that what happens in a specific group and setting is not fully transferrable to other groups (interactions, learn from each other is dependent on the specific assembly of the group). All participants in our pilot study were Caucasian, were born in Belgium, lived in the same region and were retired ( 2 participants worked). So some of the hindering or supporting elements/processes identified might be very specific to these groups. However, since our study involved five different groups, in a primary care setting, with participants of different education levels, living conditions (alone or not) and involvement in community life, a number of the recommendations to support personal change (attitudes and behaviour) in group sessions could be more widely used. A third point to be addressed, is the fact that a number of participants did not follow the full basic program of 5 sessions. We know this was partly due to holidays and sickness (so not linked to the program itself) but it might have influenced the process of personal change in individuals. Nevertheless, we believe that the SWOT analysis based on all the groups, focussing on the strengths and weaknesses of the program, does provides relevant information for improving group programs and supporting educators in delivering them. The deployment of the 'real life recordings' was also the major strong point of our study. It allowed to depict the spontaneous processes during the actual education sessions (non-participating observation) and therefore enhances credibility. ${ }^{[30]}$ It permitted a detailed evaluation of the session-processes which in turn led to formulation practical recommendations. In addition, it allowed checking to what extent the intervention was faithful to the protocol (fidelity testing), an important element of implementation and evaluation research. ${ }^{[31]} \mathrm{We}$ involved researchers from different backgrounds to support a more comprehensive analysis and interpretation of the data (researcher triangulation) and adopted a reflective research process. This supports the credibility and confirmability and hence the quality of our research. ${ }^{[30,32]}$

\subsection{Implications for practice and future research}

Our study holds a number of recommendations to support the process of personal change in diabetes self-management during group sessions in practice. First, it is important to take a whole process approach and focus on the link between barriers/facilitators and behaviour change and clarify this link and make it concrete to participants, as suggested by other researchers. ${ }^{[16,23,25]}$ Second, we should try to find a balance between the information needs of the participants and covering the aspects health care providers find important. A possible solution could be (as we partially succeeded in) to structure the goal-setting process but leave the choice of the topics to the participants. If we really want to become very practical, set goals, make plans, we may have to "direct" this process and ask for a minimum of engagement. Third, diabetes educators need to find a balance between their three different roles. This means trying to diminish the impact of the "expert" role by being attentive not to give too much information or go into too much detail. We should be responding to questions instead of lecturing and in this way creating the right atmosphere and expectations, a point made by patients and researchers elsewhere. ${ }^{[33,34]}$ Short answers to patients' own questions are preferable. So finding the balance in information is a challenge. Furthermore, as a "coach" taking on an empowerment attitude is worthwhile and in our program this led to a very supportive atmosphere and a number of people making concrete changes and feeling better. At the same time it is important to keep in mind the "moderator" role. This entails preventing long monologues (by co-educators or participants) or going into too much detail, and keeping a structure and focus while allowing and stimulating enough interaction and group input. From our study, it is obvious that educators have an important but difficult role. This is an observation shared by other researchers. ${ }^{[35]}$ So a next recommendation is to provide the coaches with professional support. Training should be provided in managing group dynamics, in dealing with, amongst others, "emotional topics" and in coaching (in order to feel more comfortable in that role). Based on our experiences we suggest that recordings of sessions can be used to prepare for the following educational session and for reflection of the coaches in team. 
Finally, research into the effects and processes of group education remain important since mixed evidence on effectiveness and poor information on mechanisms are currently available. ${ }^{[36,37]}$ Our study is a first step in offering a program/process for supporting the personal change process in self-management and in trying to identify and describe the mechanism responsible for improvements in selfmanagement and consequently in outcomes. More research is needed to confirm, refine and complement these recommendations and to explore the link between specific program components and improved outcomes into more detail. Future programs should also pay attention to whether a fixed set of topics or a more free approach yields the best results. We also need to focus on how a structured program can be followed within the patients' agenda.

\section{Conclusions}

Based on the audio-recordings of the group sessions, we can conclude that many people did change their self-management behaviour (or started reflecting on it) while following the program. We were able to document concrete changes people made but we could only identify a few links between specific program components and specific changes processes (e.g. pedometer, nutritional information). However, the SWOT analysis provided interesting knowledge that can inform future programs and support educators during group sessions. First, a flexible approach may be preferable to stage-specific approaches because of mutual differences between participants. Individual people could also be in different stages for different behaviours. In addition, the analysis drew attention to the fact that not everybody needs to change behaviour. What a program should aim for, is that everyone starts reflect- ing and subsequently takes an informed decision to change or not. Thinking about changing could lead to actual change at a later stage. Next, diabetes educators should find a balance between their three different roles (expert, coach, and moderator) and should be provided with professional support. Finally, more research is needed to confirm, refine and complement these recommendations and to explore how a structured program can be followed within the patients' agenda.

\section{ACKNOWLEDGEMENTS}

We would like to thank the diabetes trained educator Lutgarde Jenkins who conducted the group sessions with a lot of care. We also like to acknowledge Bénédicte Deforche, Miriam Van Agtmaal and Annemie Quintyn for sharing their expertise during some of the sessions of the group programme. We are grateful to the people with diabetes for their enthusiastic participation the group sessions. We also wish acknowledge the non-author members of the scientific committee and local steering group of the project: Marc Amant, Jan De Maeseneer, Luc Feyen, Caroline Haeck, Désirée Lambrecht, Frank Nobels, Rudy Saeys, Emmanuel Samyn, Boris Snauwaert, Etienne Vermeire, Paul Van Crombrugge, Marie Vandekerckhove, Anne-Marie Vandenberk and Magda Wijns. Finally we want to express our gratitude to the Belgian Government (National Health Insurance Institute) who funded this project.

\section{CONFliCtS OF INTEREST Disclosure}

All authors declare that they have no significant competing financial, professional, or personal interests that might have influenced the performance or presentation of the work described in this manuscript.

\section{REFERENCES}

[1] Anderson B, Funnell M. The art of empowerment. Stories and strategies for diabetes educators. United States: American Diabetes Association; 2005.

[2] Anderson B, Funnell M, Carlson A, et al. Facilitating self-care through empowerment. Psychology in Diabetes Care. Chichester, UK: John Wiley § Sons Ltd. 2000. 69-97. http://dx.doi.org/1 $0.1002 / 0470846569 . \mathrm{ch} 4$

[3] Bodenheimer T, Lorig K, Holman H, et al. Patient self-management of chronic disease in primary care. JAMA. 2002; 288: 2469-75. PMid: 12435261. http://dx.doi.org/10.1001/jama.288.19.2469

[4] National Institute for Health and Clinical Excellence. Type 2 diabetes in adults: management. NICE guidelines [NG28], Published December 2015. Available from: http://www.nice.org.uk/guidance /ng28

[5] American Diabetes Association. Standards of medical care in diabetes - 2015. Diabetes Care 2015; 38: S1-S2. Available from: http://dx.doi.org/10.2337/dc15-S001.
[6] Haas L, Maryniuk M, Beck J, et al. National standards of diabetes self-management education support. Diabetes Care. 2012; 35: 2393 2401. http://dx.doi.org/10.2337/dc12-1707

[7] Colagiuri R, Giris S, Eigenman C, et al. National evidence based guideline for patient education in type 2 diabetes. Diabetes Australia and the NHMRC, Canberra 2009. Available from: http://static .diabetesaustralia.com.au/s/fileassets/diabetes-a ustralia/b9b8789d-c7ba-473d-bd49-0b7d793a0835.pdf

[8] Deakin T, Mcshane C, Cade J, et al. Group based training for selfmanagement strategies in people with type 2 diabetes. Cochrane Database Syst Rev. 2005; 2: CD003417. http://dx.doi .org/10. 1002/14651858. cd003417.pub2

[9] Trento M, Passera P, Borgo E, et al. A 5-year randomized controlled study of learning, problem solving ability, and quality of life modifications in people with type 2 diabetes managed by group care. Diabetes Care. 2004; 27: 670-5. PMid: 14988283. http: //dx.doi.org/10.2337/diacare.27.3.670

[10] Pibernik-Okanovic M, Prasek M, Poljicanin-Filopovic T, et al. Ef- 
fects of an empowerment-based psychosocial intervention on quality of life and metabolic control in type 2 diabetic patients. Pat edu couns. 2004; 52: 193-9. http://dx.doi.org/10.1016/S0738 -3991 (03) 00038-7

[11] Deakin T, Cade J, Williams R, et al. Structured patient education: the diabetes X-PERT programme makes a difference. Diabetic Med. 2006; 23: 944-54. http://dx.doi.org/10.1111/j.1464-549 1.2006.01906. $\mathrm{x}$

[12] Steinsbekk A, Rygg L, Lisulo M, et al. Group based diabetes selfmanagement education compared to routine treatment for people with type 2 diabetes. A systematic review with meta-analysis. BMC Health Services Research. 2012; 12: 213. http://dx.doi.org/1 $0.1186 / 1472-6963-12-213$

[13] Rogers J. Guidance on delivering effective group education. British Journal of community nursing. 2006; 11(11): 476-82. PMid: 17170648. http://dx.doi.org/10.12968/bjcn.2006.11.11 22276

[14] Bastiaens H, Sunaert P, Wens J, et al. Supporting diabetes selfmanagement in primary care: Pilot study of a group-based programme focussing on diet and exercise. Primary Care Diabetes. 2009; 3: 103-9. http://dx.doi.org/10.1016/j.pcd.2009.02.001

[15] Sunaert P, Bastiaens H, Fyen L, et al. Implementing a program for type 2 diabetes based on the Chronic Care Model in a hospital-centred health care system: "The Belgian experience". BMC Health Services Research. 2009; 9: 152. http://dx.doi.org/10.1186/1472-6 963-9-152

[16] Doherty Y, James P, Roberts S. Stages of change counselling. Psychology in diabetes care. Chichester, UK: John Wiley \& Sons Ltd; 2000. Chapter 5, Stage of Change Counselling; p. 99-139.

[17] Baranowski T, Perry C, Parcel G. How individuals, environments, and health behaviour interact. Health behaviour and health education. San Francisco:John Wiley \& sons; 2002. p. 165-84.

[18] Kirchbaum K. Exploring the connection between self-efficacy and effective diabetes self-management. Diab. Educ. 2003; 29(4): 653-62. http://dx.doi.org/10.1007/s10865-009-9233-4

[19] Glanz K, Rimer B, Lewis F. Health behavior and health education. Theory, research and practice. San Francisco, CA. Jossey-Bass, 2002.

[20] Mayring P. Qualitative content analysis. Forum Qualitative social research. 2000; 1(2). http://www.qualitative-research.ne t/index.php/fqs/article/view/1089/2385

[21] Elo S, Kyngäs H. The qualitative content analysis process. Journal of Advanced Nursing. 2007; 62: 107-15. PMid: 18352969. http://dx.doi.org/10.1111/j.1365-2648.2007.04569.x

[22] Available from: http://rapidbi.com/created/SWOTanalys is.html\#SWOTmodel

[23] Weinstein N, Rothman A, Sutton S. Stage theories of health behaviour: conceptual and methodological issues. Health psychology. 1998; 17(3): 290-9. PMid: 9619480. http://dx.doi.org/10.10 37/0278-6133.17.3.290

[24] Peyrot M, Rubin R. Behavioral and psychosocial interventions in diabetes. Diabetes care. 2007; 30(10): 2433-40. PMid: 17666457 http://dx.doi.org/10.2337/dc07-1222
[25] Bridle C, Riemsma R, Pattenden J, et al. Systematic review of the effectiveness of health behaviour interventions based on the transtheoretical model. Psychol Health. 2005; 20(3): 283-302. http: //dx.doi.org/10.1080/08870440512331333997

[26] Schüz B, Sniehotta F, Mallach N, et al. Predicting transitions form pre-intentional, intentional and actional stages of change. Health educ res. 2009; 24(1): 64-75. PMid: 18245046. http://dx.doi.o $\mathrm{rg} / 10.1093 /$ her/cym092

[27] Rollnick S, Kinnersley P, Scott N. Methods of helping patients with behavioural change. BMJ. 1999; 307: 188-90. http://dx.doi.o $\mathrm{rg} / 10.1136 / \mathrm{bmj} .307 .6897 .188$

[28] Skinner C, Carey M, Cradock S, et al. 'Educator talk' and patient change: some insights from the DESMOND randomized controlled trial. Diabet Med. 2008; 25: 1117-20. http://dx.doi .org/10.11 $11 / j .1464-5491.2008 .02492 . x$

[29] Murray S, Kendall M, Carduff E, et al. Use of serial qualitative interviews to understand patients' evolving experiences and needs. BMJ 2009; 20: 339. http://dx.doi.org/10.1136/bmj.b3702

[30] Kuper A, Lingard L, Levinson W. Critically appraising qualitative research. BMJ. 2008; 7: 337. http://dx.doi.org/10.1136/bmj .a1035

[31] Glasgow RE. RE-AIMing research for applications: Ways to improve evidence for family medicine. J Am Board Fam Med. 2006; 19: 11-9. PMid: 16492000. http://dx.doi.org/10.3122/jabfm.19.1. 11

[32] Finlay L. Rigour, Ethical Integrity, or Artistry? Reflexively Reviewing Criteria for evaluating Qualitative Research. "British Journal of Occupational Therapy. 2006; 69: 319-26. http://dx.doi.org/1 $0.1177 / 030802260606900704$

[33] Kettunen T, Liimatainen L, Villberg J, et al. Developing empowering health counselling measurement: preliminary results. Pat educ couns 2006; 64: 159-66. http://dx.doi.org/10.1016/j.pec. 2005. 12.012

[34] Weis M. Empowerment: a patient's perspective. Diabetes spectrum. 2006; 19: 116-8. http://dx.doi.org/10.2337/diaspect.19 .2 .116

[35] Anderson T, Hempler N, Willaing I. Educator challenges using participatory methods in group-based patient education. Health Education 2014; 114: 152-65. http://dx.doi.org/10.1108/HE-07-201 3-0032

[36] Davies M, Heller S, Skinner T, et al. Effectiveness of the diabetes education and self-management for ongoing and newly diagnosed (DESMOND) programme for people with newly diagnosed diabetes type 2 diabetes: cluster randomised controlled trial. BMJ. 2008; 336 : 491-5. http://dx.doi.org/10.1136/bmj . 39474.922025

[37] Khunti K, Gray L, Skinner T, et al. Effectiveness of a diabetes education and self-management programme (DESMOND) for people with newly diagnosed type 2 diabetes mellitus: three year followup of a cluster randomized trial in primary care. BMJ. 2012; 344 http://dx.doi.org/10.1136/bmj.e2333 